\title{
The effect of sperm and egg genotype on the incidence of chromosomal anomalies in mouse embryos fertilized in vitro
}

\author{
I. Maudlin* and Lynn R. Fraser* $\dagger$ \\ *Clinical Research Centre, Watford Road, Harrow, Middlesex, HAl 3UJ, and \\ †Department of Obstetrics \& Gynaecology, University College Hospital, London, WCIE 6DH, U.K.
}

\begin{abstract}
Summary. Analysis of the chromosomes of 1-cell mouse embryos fertilized in vitro showed that the incidence of polyploidy is independent of both sperm and egg genotype. No significant differences were detected between groups of eggs from 5 strains of mice fertilized by spermatozoa from a single strain, TO, or between groups of (C57BL/ $10 \times \mathrm{CBA}) \mathrm{F}_{1}$ eggs fertilized by spermatozoa from 2 strains, CBA/H-T6 and TO, although there was significant heterogeneity between individual males in the latter set of experiments. While the majority of polyploids were triploids resulting from dispermic fertilization, some derived from diploid spermatozoa were also found.
\end{abstract}

\section{Introduction}

The penetration of the zona pellucida by more than one spermatozoon has been shown by Braden (1958) and, more recently, Krzanowska (1970) to be correlated with the sperm genotype. However, 'supplementary' spermatozoa do not necessarily affect the resultant embryo since they usually fail to fuse with the vitellus. Braden (1957) established that the genotype of mouse eggs was important in determining the incidence of abnormalities of egg maturation such as suppression of second polar body formation, but was unable to demonstrate any effect of genotype on the ability of spermatozoa to enter the egg proper, and it has been argued that penetration of the vitellus is dependent mainly on egg genotype (Beatty, 1970).

The aim of the present work was to determine the separate effects of sperm and egg genotype, not on the incidence of supplementary spermatozoa, which may have no significance in embryogenesis, but on the incidence of polyspermy determined by examination of the chromosome complements of 1-cell mouse embryos. Since the incidence of polyspermy is low among mouse embryos fertilized in vivo (Donahue, 1972; Ford \& Evans, 1973), making assessment of significant variation difficult, we used an in-vitro fertilization system that has been shown to give consistently high proportions of polyploid embryos (Fraser, Zanellotti, Paton \& Drury, 1976; Maudlin \& Fraser, 1977).

\section{Materials and Methods}

Two- to 4-month old TO and CBA/H-T6 males and virgin females of the strains TO, CBA, C57BL/ $10, \mathrm{DBA} / 2$ and $(\mathrm{C} 57 \mathrm{BL} / 10 \times \mathrm{CBA}) \mathrm{F}_{1}$ females were obtained from the Specific Pathogen Free breeding unit of the Clinical Research Centre. For experiments on fertilization in vitro, females were induced to superovulate by injections of $7 \cdot 5$ i.u. PMSG (Gestyl: Organon) and, approximately $48 \mathrm{~h}$ later, 5.0 i.u. hCG (Pregnyl: Organon). Unfertilized eggs were recovered $13 \mathrm{~h}$ after the hCG injection and the methods and media used were those described by Fraser \& Drury (1975). For experiments on sperm genotype, each sperm suspension was prepared from 1 rather than 2 males, while for experiments on egg genotype, 2 TO males were used for each epididymal sperm suspension to minimize possible variation between individual males. Spermatozoa were allowed to disperse for 20 min and then diluted to a concentration of $2 \times 10^{6}$ spermatozoa $/ \mathrm{ml}$. The unfertilized eggs were released directly into the sperm suspensions and incubated at $37^{\circ} \mathrm{C}$ for $6 \mathrm{~h}$ in an atmosphere of $5 \% \mathrm{O}_{2}+5 \%$ $\mathrm{CO}_{2}+90 \% \mathrm{~N}_{2}$. The eggs were then washed twice in culture medium and incubated overnight in medium containing $10^{-5} \mathrm{~mm}$-vinblastine sulphate (Velbe: Lilly). Chromosome preparations were made from the 1-cell embryos (Maudlin \& Fraser, 1977).oaded from Bioscientifica.com at 04/26/2023 07:14:40AM 
For experiments on fertilization in vivo, females were induced to superovulate as described above, with the hCG being given 12-13 h before the estimated time of spontaneous ovulation, and paired overnight with TO or T6 males. Females with vaginal plugs the next morning were killed in the afternoon; 1-cell embryos were recovered, cultured overnight in Velbe-containing medium and then prepared for chromosomal analysis.

In the experiments on sperm genotype, the overall level of fertilization determined from the number of eggs possessing second polar bodies was $86 \%$ with TO and $80 \%$ with T6 spermatozoa. In the experiments on egg genotype the levels of fertilization in vitro were: TO, $88 \% ; \mathrm{CBA}, 84 \%$; C57BL $/ 10,96 \% ; \mathrm{DBA} / 2,89 \% ; \mathrm{F}_{1}, 78 \%$.

\section{Results}

Sperm genotype

\section{Polyploidy}

Series 1 . The incidence of polyploidy detected in 1-cell embryos derived from $\mathrm{F}_{1}$ eggs fertilized in vitro with spermatozoa from individual TO and T6 males is shown in Table 1 . The incidence of polyploidy in these embryos ranged from 0 to $30.4 \%$ with the T6 spermatozoa and from $0.8 \%$ to $41.5 \%$ with TO spermatozoa. Chi-square tests showed both groups to be greatly heterogeneous $(P<0.001)$, indicating significant variation between individual males.

In order to assess these results, the origin of the polyploidy had to be established. In the experiments with T6 mice, the male chromosome complement in 1-cell embryos can readily be distinguished by the chromosome marker. However, even in strains without markers, it is possible to distinguish maternally and paternally derived chromosomes in 1-cell embryos because the maternal chromosomes are more condensed than the paternal set when the embryos are examined under these experimental conditions. This phenomenon was noted by McGaughey \& Chang (1971) and Donahue (1972) and has been utilized by Hansmann (1973), Brewen, Payne, Jones \& Preston (1975) and ourselves (Maudlin \& Fraser, 1977). By using these criteria all of the 62 polyploid embryos were found to be polyandric; 61 were triploid and one was a trispermic tetraploid. Two of the triploid embryos were fertilized by diploid spermatozoa, one TO and one T6 (Pl. 1, Fig. 1).

Table 1. Incidence of polyploidy (n) in 1-cell mouse embryos (N) fertilized in vitro with spermatozoa obtained from individual CBA/H-T6 and TO males

\begin{tabular}{|c|c|c|c|c|c|c|}
\hline \multirow[b]{2}{*}{ Exp. } & \multicolumn{3}{|c|}{$\mathrm{F}_{1}$ 우 $\times \mathrm{T} 6$ ठ } & \multicolumn{3}{|c|}{$\mathrm{F}_{1}$ 우 $\times \mathrm{TO}$} \\
\hline & $\mathbf{N}$ & $\mathrm{n}$ & $\%$ & $\mathbf{N}$ & $\mathrm{n}$ & $\%$ \\
\hline 1 & 37 & 0 & 0 & 66 & 7 & $10 \cdot 6$ \\
\hline 2 & 39 & 6 & $15 \cdot 4$ & 26 & 3 & $11 \cdot 5$ \\
\hline 3 & 31 & 0 & 0 & 41 & 17 & $41 \cdot 5$ \\
\hline 4 & 39 & 5 & $12 \cdot 8$ & 131 & 1 & 0.8 \\
\hline 5 & 5 & 0 & 0 & 63 & 10 & 15.9 \\
\hline 6 & 9 & 2 & $22 \cdot 2$ & 24 & 1 & 4-2 \\
\hline 7 & 23 & 7 & $30 \cdot 4$ & 25 & 2 & $8 \cdot 0$ \\
\hline 8 & 68 & 1 & $1 \cdot 5$ & & & \\
\hline Total & 251 & 21 & $8 \cdot 4$ & 372 & 41 & $11 \cdot 0$ \\
\hline
\end{tabular}

Series 2 . Because of the heterogeneity between males detected in the first series of experiments in vitro, a second series was carried out in which a measure of the performance of each male in vivo was obtained before in-vitro experimentation (Table 2).

Four of the 5 T6 males used produced very low levels of polyploidy in vivo and in vitro, while one (Male 5) produced a significantly greater proportion of polyploid embryos in vitro than in vivo. A comparison of the in-vivo and in-vitro data was carried out with the Generalized Linear Interactive Modelling technique (GLIM ; Nelder, 1974) which allowed for the heterogeneity within groups: 2 his 
Table 2. Incidence of polyploidy (n) in 1-cell mouse embryos $(\mathrm{N})$ fertilized in vivo and in vitro by the same individual CBA/H-T6 and TO males

\begin{tabular}{|c|c|c|c|c|c|c|c|c|}
\hline \multicolumn{2}{|l|}{ Male } & \multirow{2}{*}{$\begin{array}{l}\text { No. of matings } \\
\text { per male }\end{array}$} & \multicolumn{3}{|c|}{ In vivo } & \multicolumn{3}{|c|}{ In vitro } \\
\hline Type & No. & & $\mathbf{N}$ & n & $\%$ & $\mathrm{~N}$ & $\mathbf{n}$ & $\%$ \\
\hline \multirow[t]{5}{*}{$F_{1} q \times T 6 \delta^{\circ}$} & 1 & 3 & 83 & 4 & 4.8 & 37 & 3 & $8 \cdot 1$ \\
\hline & 2 & 3 & 75 & 2 & 2.7 & 49 & 1 & $2 \cdot 0$ \\
\hline & 3 & 4 & 121 & 0 & 0 & 54 & 0 & 0 \\
\hline & 4 & 3 & 100 & 0 & 0 & 61 & 0 & 0 \\
\hline & 5 & 3 & 81 & 1 & $1 \cdot 2$ & 52 & 6 & $11 \cdot 5$ \\
\hline Total & & & 460 & 7 & $1 \cdot 5$ & 253 & 10 & 3.9 \\
\hline \multirow[t]{4}{*}{$F_{1}$ O $\times \mathrm{TO}_{\delta}{ }^{*}$} & 1 & 6 & 99 & 2 & $2 \cdot 0$ & 72 & 3 & 4.5 \\
\hline & 2 & 1 & 14 & 0 & 0 & 45 & 17 & 37.8 \\
\hline & 3 & 3 & 68 & 1 & 1.5 & 51 & 11 & $21 \cdot 5$ \\
\hline & 4 & 5 & 86 & 2 & $2 \cdot 3$ & 60 & 7 & $11 \cdot 6$ \\
\hline Total & & & 267 & 5 & 1.9 & 228 & 38 & $16 \cdot 6$ \\
\hline
\end{tabular}

analysis showed that there was no significant difference between the results in vivo and in vitro $\left(t_{4 \mathrm{~d} . \mathrm{f} .}=\right.$ $1.97, P=$ N.S.). Three of the 4 TO males produced significantly greater levels of polyploidy in vitro than in vivo; the overall production of $16.6 \%$ polyploid embryos by these males in vitro was significantly greater than the level $(1.9 \%)$ obtained in vivo $\left(t_{3 \text { d.s. }}=3.43,0.05<P<0.01\right)$ : the GLIM technique allowed for the paired nature of the observations.

All of the $17 \mathrm{~F}_{1} \times \mathrm{T} 6$ polyploid embryos from the in-vivo and in-vitro fertilization experiments were triploid; 16 were dispermic and 1 had been fertilized in vitro by a diploid spermatozoon from Male 7. Of the $43 F_{1} \times$ TO polyploid embryos from both experiments, 40 were triploid and the other 3 , all found in the in-vitro group, were tetraploid. Five diploid spermatozoa were detected in these $F_{1} \times$ TO embryos, one being in eggs fertilized in vivo by Male 3, which also produced 3 of the 4 diploid spermatozoa found in the in-vitro group.

Although the overall level of polyploidy in vitro was greater with TO males than with T6 males, GLIM analysis showed that this difference was not significant when the variation within groups was allowed for $\left(t_{7 \text { d.f. }}=1 \cdot 78, P=\right.$ N.S. $)$.

\section{Aneuploidy}

From the cross $F_{1} \times \mathrm{T} 6,98 \%$ of the embryos fertilized in vitro could be scored for aneuploidy compared with $63 \%$ of the controls fertilized in vivo; the corresponding figures for the $F_{1} \times$ TO embryos were 71 and $51 \%$. Since no significant differences were detected in the incidence of aneuploidy between male and female chromosome complements, the figures were combined (Table 3). The incidence of aneuploidy was remarkably constant at about $2 \%$ for both strain combinations whether fertilized in vitro or in vivo. Furthermore, no significant differences were detected in the incidence of monosomic and trisomic aneuploids. An aneuploid embryo with a trisomic male complement is shown in Pl. 1, Fig. 2.

Table 3. The numbers ( $\%$ in parentheses) of aneuploid first-cleavage mouse embryos from two strain combinations fertilized in vitro and in vivo

\begin{tabular}{|c|c|c|c|c|c|}
\hline \multirow[b]{2}{*}{ Strain } & \multirow[b]{2}{*}{ Fertilization } & \multicolumn{4}{|c|}{ No. of embryos } \\
\hline & & Scored & Monosomic & Trisomic & Total aneuploid \\
\hline $\mathrm{F}_{1}+\mathrm{q} \times \mathrm{T} 6{ }^{*}$ & $\begin{array}{l}\text { In vitro } \\
\text { In vivo }\end{array}$ & $\begin{array}{l}606 \\
324\end{array}$ & $\begin{array}{l}7(1 \cdot 2) \\
3(0.9)\end{array}$ & $\begin{array}{l}6(1 \cdot 0) \\
3(0 \cdot 9)\end{array}$ & $\begin{array}{c}13(2 \cdot 1) \\
6(1 \cdot 8)\end{array}$ \\
\hline $\mathrm{F}_{1}$ 우 $\times \mathrm{TO}^{*}$ & $\begin{array}{l}\text { In vitro } \\
\text { In vivo }\end{array}$ & $\begin{array}{l}595 \\
205\end{array}$ & $\begin{array}{l}3(0 \cdot 5) \\
2(1 \cdot 0)\end{array}$ & $\begin{array}{r}5(0 \cdot 8) \\
\mathrm{fr}(0.5) \mathrm{s}\end{array}$ & $\begin{array}{r}\mathbf{8}(\mathbf{1} \cdot \mathbf{3}) \\
\text { entifi } \mathbf{3}(\mathbf{1} \cdot \mathbf{5}) \text { at }\end{array}$ \\
\hline
\end{tabular}




\section{Polyploidy}

\section{Egg genotype}

The incidence of polyploidy in 1-cell embryos derived from eggs, of 5 strains of mouse female, fertilized in vitro and in vivo by TO spermatozoa is shown in Table 4. Chi-square tests for heterogeneity revealed no significant variation between embryos from individual matings either between or within strains in vivo. Among the embryos fertilized in vitro, only two strains, DBA/2 and C57BL/10, showed significant heterogeneity between experiments, but these were the two strains in which the smallest number of trials was carried out. Tests for heterogeneity between strains in vitro showed no significant differences, but there were significant differences between in vivo and in vitro levels of polyploidy for all the strains examined.

Two of the polyploid embryos were digynic in origin (see Pl. 2, Fig. 3); both were found in vivo, one from a C57BL/10 and one from a CBA female. Nine triploid embryos, 1 or 2 from each strain examined, were fertilized by diploid spermatozoa, all in vitro. Two tetraploid embryos, $1 \mathrm{C} 57 \mathrm{BL} / 10$ and 1 TO, were found, both in the in-vitro group. The remaining 139 polyploid embryos were all triploids formed as a result of dispermic fertilization in vitro or in vivo.

Table 4. Incidence of polyploidy $(\mathrm{n})$ in 1-cell mouse embryos (N) fertilized in vivo and in vitro from eggs obtained from 5 strains of female and spermatozoa from the TO strain

\begin{tabular}{|c|c|c|c|c|c|c|c|c|}
\hline \multirow[b]{2}{*}{ Female gamete } & \multicolumn{4}{|c|}{ In vitro } & \multicolumn{4}{|c|}{ In vivo } \\
\hline & No. of exps. & $\mathbf{N}$ & $\mathrm{n}$ & $\%$ & No. of matings & $\mathbf{N}$ & $\mathbf{n}$ & $\%$ \\
\hline $\mathrm{DBA} / 2$ & 4 & 178 & 42 & $23 \cdot 6$ & 3 & 65 & 2 & $3 \cdot 1$ \\
\hline$(\mathrm{C} 57 \mathrm{BL} / 10 \times \mathrm{CBA}) \mathrm{F}_{1}$ & 9 & 166 & 31 & $18 \cdot 7$ & 4 & 267 & 5 & 1.9 \\
\hline C57BL/10 & 3 & 111 & 24 & $21 \cdot 6$ & 3 & 58 & 3 & $5 \cdot 2$ \\
\hline TO & 9 & 162 & 26 & 16.0 & 4 & 167 & 1 & 0.6 \\
\hline $\mathrm{CBA}$ & 5 & 103 & 17 & $16 \cdot 5$ & 3 & 59 & 1 & $1 \cdot 7$ \\
\hline Total & & 720 & 140 & $19 \cdot 4$ & & 616 & 12 & 1.9 \\
\hline
\end{tabular}

\section{Aneuploidy}

The number of aneuploid chromosome complements found is shown in Table $5 ; 64 \%$ of the preparations of embryos fertilized in vitro were sufficiently well spread to allow counts of individual chromosomes to be made, while only $55 \%$ of the in-vivo preparations were thus adequate. No significant differences were found between the incidence of male- and female-derived monosomy and trisomy, and the data were therefore combined. Also included in this table is a single tetrasomic (22)

Table 5. The numbers ( $\%$ in parentheses) of aneuploid 1-cell mouse embryos derived from eggs of 5 strains of female and fertilized in vitro and in vivo with TO spermatozoa

\begin{tabular}{|c|c|c|c|c|c|}
\hline \multirow[b]{2}{*}{ Female gamete } & \multirow[b]{2}{*}{ Fertilization } & \multicolumn{4}{|c|}{ No. of embryos } \\
\hline & & Scored & Monosomic & Trisomic & Total aneuploid \\
\hline $\mathrm{DBA} / 2$ & $\begin{array}{l}\text { In vitro } \\
\text { In vivo }\end{array}$ & $\begin{array}{r}174 \\
20\end{array}$ & $\begin{array}{l}3(1 \cdot 7) \\
0(0)\end{array}$ & $\begin{array}{l}1(0.6) \\
0(0)\end{array}$ & $\begin{array}{l}4(2 \cdot 3) \\
0(0)\end{array}$ \\
\hline $\begin{array}{l}(\mathrm{C} 57 \mathrm{BL} / 10 \times \\
\mathrm{CBA}) \mathrm{F}_{1}\end{array}$ & $\begin{array}{l}\text { In vitro } \\
\text { In vivo }\end{array}$ & $\begin{array}{l}166 \\
205\end{array}$ & $\begin{array}{l}2(1 \cdot 2) \\
2(1 \cdot 0)\end{array}$ & $\begin{array}{l}2(1 \cdot 2) \\
1(0 \cdot 5)\end{array}$ & $\begin{array}{l}4(2 \cdot 4) \\
3(1 \cdot 5)\end{array}$ \\
\hline C57BL/10 & $\begin{array}{l}\text { In vitro } \\
\text { In vivo }\end{array}$ & $\begin{array}{r}110 \\
47\end{array}$ & $\begin{array}{l}2(1 \cdot 8) \\
0(0)\end{array}$ & $\begin{array}{l}1(0.9) \\
0(0)\end{array}$ & $\begin{array}{l}3(2 \cdot 7) \\
0(0)\end{array}$ \\
\hline TO & $\begin{array}{l}\text { In vitro } \\
\text { In vivo }\end{array}$ & $\begin{array}{l}160 \\
215\end{array}$ & $\begin{array}{l}5(3 \cdot 1) \\
1(0 \cdot 5)\end{array}$ & $\begin{array}{l}2(1 \cdot 3) \\
2(0.9)\end{array}$ & $\begin{array}{l}7(4 \cdot 3) \\
3(1 \cdot 4)\end{array}$ \\
\hline CBA & $\begin{array}{l}\text { In vitro } \\
\text { In vivo }\end{array}$ & $\begin{array}{l}90 \\
29\end{array}$ & $\begin{array}{c}\mathbf{1}(\mathbf{1} \cdot \mathbf{1}) \\
\mathbf{0}_{\mathrm{d}}(\mathbf{0})_{\text {from }}\end{array}$ & $\begin{array}{c}\mathbf{0}(\mathbf{0}) \\
\mathbf{O}_{(\mathbf{0})}\end{array}$ & $\begin{array}{c}\mathbf{1}(\mathbf{1} \cdot \mathbf{1}) \\
\mathbf{0}(\mathbf{0})_{26 / 2023}\end{array}$ \\
\hline
\end{tabular}



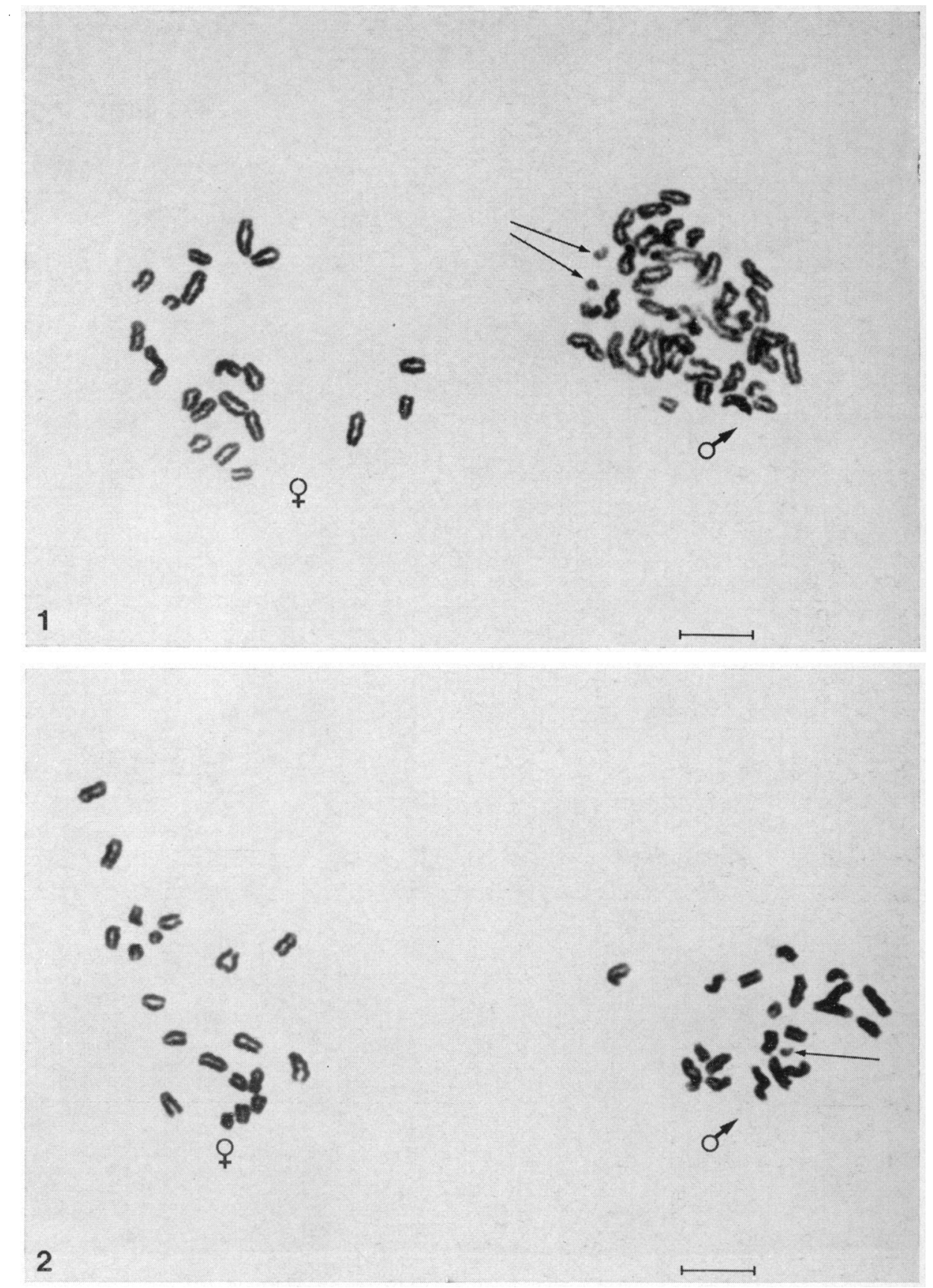

First-cleavage mouse embryos fertilized in vitro showing (Fig. 1) a triploid chromosome complement produced by a diploid CBA/H-T6 spermatozoon, and (Fig. 2) a trisomic chromosome complement from a CBA/H-T6 spermatozoon. $\delta=$ male complement; $q=$ female complement; the T6 marker chromosome is arrowed. The bars represent $10 \mu \mathrm{m}$. 


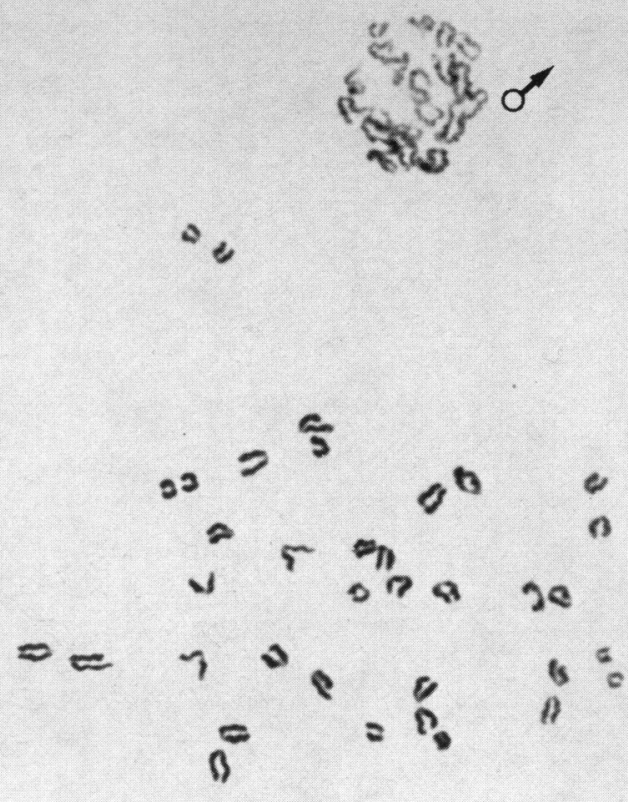

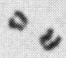

3

a
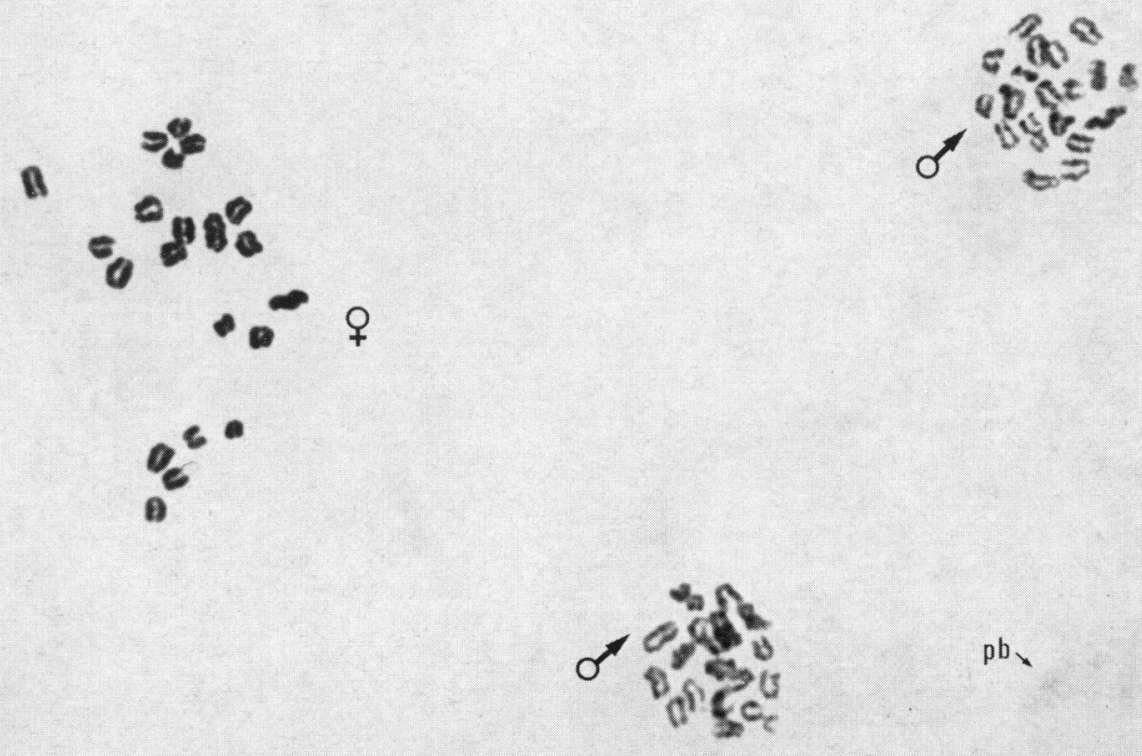

4

First-cleavage mouse embryos fertilized in vitro showing a triploid chromosome complement produced by (Fig. 3) digyny and (Fig. 4) dispermy. Note the tetrasomic (22) female complement in Fig. 4. $\delta=$ male complement; $q=$ female complement $; \mathrm{pb}=$ second polar body. The bars represent $10 \mu \mathrm{m}$. 
complement found in a C57BL/10 female (see Pl. 2, Fig. 4). No significant differences were found in levels of aneuploidy between embryos fertilized in vitro and in vivo, the overall figure of $2 \cdot 1 \%(25 /$ 1217) being very similar to that found in the first series of experiments (Table 3 ).

\section{Discussion}

By chromosomal analysis of 1-cell mouse embryos we have shown that the incidence of polyploidy is unaffected by sperm or egg genotype. The results of the present in-vitro fertilization experiments have demonstrated that the incidence of polyspermic polyploidy varies according to the strain of mouse and the individual male used as sperm donor. However, the variation between strains of sperm donor, TO and T6, was not significant. Similarly, when eggs obtained from 5 strains of mice were fertilized in vitro by TO spermatozoa, no significant differences could be detected in the levels of polyploidy, but as shown in previous studies (Fraser et al., 1976; Maudlin \& Fraser, 1977), the incidence of polyploidy was significantly greater among embryos fertilized in vitro by TO spermatozoa than among those fertilized in vivo.

Although most of the polyploid embryos detected in the present study were dispermic triploids (see PI. 2, Fig. 4), diploid spermatozoa were also found (see Pl. 1, Fig. 1). Krzanowska (1974) suggested that the uterotubal junction acted as a block to the passage of diploid spermatozoa in the mouse, but, because of the small numbers examined, could not conclude that this block was absolute. In the present experiments diploid spermatozoa were found not only in embryos fertilized in vitro, confirming our recent findings (Maudlin \& Fraser, 1977), but also in one embryo fertilized in vivo. This indicates that the uterotubal junction is not totally effective in excluding diploid spermatozoa from the site of fertilization in the mouse. The diploid spermatozoon detected in an embryo fertilized in vivo came from the same TO male which produced 3 of the 4 diploid spermatozoa found among the embryos fertilized in vitro in the same series, suggesting that the production of diploid spermatozoa is not random and may be characteristic of individual males.

In addition, 2 embryos from the in-vivo groups were digynic triploids. Very high levels of digyny have been reported in some studies but these have been among strains of mice susceptible to the production of digynic eggs by retention of the second polar body. When examining the incidence of polyploidy in 6-7-day-old mouse embryos, Takagi \& Sasaki (1976) found 3.7\% digynic embryos in spontaneously ovulating females compared with $19.2 \%$ in superovulating females. However, the high levels in the control group suggest that the strain used $(\mathrm{A} / \mathrm{He})$ is similar to the 'silver' strain, studied by Beatty (1970), which is predisposed towards retention of the second polar body. In a study of 1-cell embryos, Donahue (1972) found only $1.2 \%$ to be triploid and this is not significantly different from the $1.5-1.9 \%$ we found after fertilization in vivo. Although Donahue did not determine the origin of this polyploidy, the incidence of digyny must have been equal to or less than $1 \cdot 2 \%$. Moreover, in a study of polyploid abortuses, Kajii \& Niikawa (1977) showed that dispermy rather than digyny was the major cause of triploidy in man.

The incidence of aneuploidy in the present study was remarkably uniform at about $2 \%$ for embryos fertilized in vitro and in vivo, being evenly divided between male- and female-derived chromosomal complements and between trisomic and monosomic anomalies. These data are in close agreement with those observed by Donahue (1972) who found $1.8 \%$ of 1 -cell embryos to be aneuploid, although Kaufman (1973) has reported a high level of aneuploidy $(8.3 \%)$ in mouse embryos at the same stage. Data from later stages of development are more plentiful; for example, Gosden (1973) described 4 trisomic embryos among 168 morulae and blastocysts $(2 \cdot 4 \%)$. In a study of post-implantation mouse embryos, Ford \& Evans (1973) found 11 aneuploids among 1924 8-11-day-old implantations $(0.6 \%)$. This figure is slightly lower than ours, but Ford \& Evans suggest that, because they found an even lower incidence in 12-15-day-old embryos, such abnormal implantations selectively degenerate, leading to conservative estimates for the primary incidence. The $2.3 \%$ of aneuploids among 1406 6-7-day-old mouse embryos reported by Takagi \& Sasaki (1976) is also in good agreement with the present results. Yamamoto, Endo \& Watanabe (1973) found no aneuploids in 14910 .5-day-old mouse fetuses, but there were 4 aneuploids among 156 fetuses $(2.6 \%)$ taken from older mothers. Our estimate of around $2 \%$ for the incidence of aneuploidy appears to fit well with most published data on mouse embryos. 
A variety of factors are known to influence the production of polyploid embryos, including delay in fertilization (Shaver \& Carr, 1967; Vickers, 1969), gonadotrophins (Fujimoto, Pahlavan \& Dukelow, 1974; Fujimoto, Passantino \& Koenczoel, 1975; Takagi \& Sasaki, 1976; Maudlin \& Fraser, 1977) and the in-vitro system itself (Fraser et al., 1976). From a study of mouse embryos fertilized in vivo, Braden (1957) concluded that the susceptibility of eggs to various types of abnormality (e.g. suppression of formation of the second polar body, 'immediate' cleavage) was controlled by the genotype of the female, but he was unable to demonstrate any effect of strain differences on the incidence of polyspermy, as distinct from the occurrence of supernumerary spermatozoa which do not fuse with the vitellus. From the present work it would appear that sperm and egg genotype do not affect the incidence of polyploidy in a consistent manner, but the significant heterogeneity observed between males indicates some effect of genotype.

We thank Linda Drury and Gillian Haynes for technical assistance, Dr C. E. Ford for his interest in this work, and Dr I. D. Hill for his assistance with the statistical analysis. One of us (I.M.), a visiting worker at the Clinical Research Centre, is a member of the M.R.C. External Scientific Staff.

\section{References}

BEATTY, R.A. (1970) The genetics of the mammalian gamete. Biol. Rev. 45, 73-119.

BRADEN, A.W.H. (1957) Variation between strains in the incidence of various abnormalities of egg maturation and fertilization in the mouse. J. Genet. 55, 476486.

BRADEN, A.W.H. (1958) Variation between strains of mice in phenomena associated with sperm penetration and fertilization. J. Genet. 56, 37-47.

Brewen, J.G., Payne, H.S., Jones, K.P. \& Preston, R.J. (1975) Studies on chemically induced dominant lethality. 1. The cytogenetic basis of MMS-induced dominant lethality in post-meiotic male germ cells. Mutation Res. 33, 239-250.

Donahue, R.P. (1972) Cytogenetic analysis of the first cleavage division in mouse embryos. Proc. natn. Acad. Sci. U.S.A. 69, 74-77.

Ford, C.E. \& Evans. E.P. (1973) Non-expression of genome unbalance in haplophase and early diplophase of the mouse and incidence of karyotype abnormality in post-implantation embryos. In Chromosomal Errors in Relation to Reproductive Failure, pp. 271-285. Eds A. Boué \& C. Thibault. INSERM, Paris.

Fraser, L.R. \& DRURY, L.M. (1975) The relationship between sperm concentration and fertilization in vitro of mouse eggs. Biol. Reprod. 13, 513-518.

Fraser, L.R., Zanellotti, H.M., Paton, G.R. \& DRURY, L.M. (1976) Increased incidence of triploidy in embryos derived from mouse eggs fertilized in vitro. Nature, Lond. 260, 39-40.

Funmoto, S., Pahlavan, N. \& Dukelow, W.R. (1974) Chromosome abnormalities in rabbit preimplantation blastocysts induced by superovulation. $J$. Reprod. Fert. 40, 177-181.

Fujimoto, S., Passantino, T.J. \& Koenczoel, I. (1975) A preliminary note on chromosome abnormalities in intratubal rabbit embryos. Proc. Japan. Acad. 51, 51-55.

Gosden, R.G. (1973) Chromosomal anomalies of pre- implantation mouse embryos in relation to maternal age. J. Reprod. Fert. 35, 351-354.

HANSMANN, I. (1973) Induced chromosomal aberrations in pronuclei, 2-cell stages and morulae of mice. Mutation Res. 20, 353-367.

KaJII, T. \& NitKAwA, N. (1977) Origin of triploidy and tetraploidy in man: 11 cases with chromosome markers. Cytogenet. Cell Genet. 18, 109-125.

Kaufman, M.H. (1973) Analysis of the first cleavage division to determine the sex-ratio and incidence of chromosome anomalies at conception in the mouse. J. Reprod. Fert. 35, 67-72.

KRZANOwSKA, H. (1970) Relation between fertilization rate and penetration of eggs by supplementary spermatozoa in different mouse strains and crosses. J. Reprod. Fert. 22, 199-204.

KrzanowsKa, H. (1974) The passage of abnormal spermatozoa through the uterotubal junction of the mouse. J. Reprod. Fert. 38, 81-90.

MAUdLIN, I. \& FRASER, L.R. (1977) The effect of PMSG dose on the incidence of chromosomal anomalies in mouse embryos fertilized in vitro. J. Reprod. Fert. 50, 275-280.

McGaughey, R.W. \& Chang, M.C. (1971) Chromosomes at prometaphase and metaphase of the first cleavage in mouse and hamster eggs. J. exp. Zool. 177, 31-40.

NELDER, J.A. (1974) GLIM (General Linear Interactive Modelling) Manual. Numerical Algorithms Group, Oxford.

Shaver, E.L. \& CaRR, D.H. (1967) Chromosome abnormalities in rabbit blastocysts following delayed fertilization. J. Reprod. Fert. 14, 415-420.

TAKAGI, N. \& SASAKI, M. (1976) Digynic triploidy after superovulation in mice. Nature, Lond. 264, 278-281.

VICKERS, A.D. (1969) Delayed fertilization and chromosomal anomalies in mouse embryos. J. Reprod. Fert. 20, 69-76.

Yamamoto, M., Endo, A. \& Watanabe, G. (1973) Maternal age dependence of chromosome anomalies. Nature, New Biol. 241, 141-142. 